\title{
Morphometry of Articular Facets of The Body of Talus
}

\author{
Dr. Veenatai.J ${ }^{1}$, Dr. V.Janaki ${ }^{2}$ \\ ${ }^{1}$ Associate Professor, Dept Of Anatomy, Rims, Adilabad, Telangana State. \\ ${ }^{2}$ Associate Professor, Dept Of Anatomy, Kakatiya Medical College, Warangal. Telangana State.
}

\begin{abstract}
:
Background: In the formation of Ankle joint, tibio-fibular mortice receives superior, medial and lateral articular surfaces of body of Talus. Because of very limited availability of the data on the Morphometry of the articular facets on the Body of the dry human Tali, this study was undertaken.

Aims: To prepare morphometric data of the articular facets on the superior, medial and lateral surfaces of body of Talus, to find if there is any difference between both the sides of measurements and to compare the results with the previous studies.

Methods and Material: 42 Dry Human Tali (20 Right and 22 Left) were measured with Digital vernier caliper for the following Measurements: 1.On the Trochlear surface: Medial length, Central length, Lateral length, Anterior width, Central width, Posterior width. 2.On the lateral triangular articular facet: Central height, Central width. 3. On the coma shaped medial articular facet: Central height, Central width.

Results: Superior Articular Surface:On the superior Articular surface, the mean values of Medial, Central and Lateral length were 28.4,29.4 and 28.4mm on Right side and 31.0, 28.0 and 30.0mm on Left side. Mean Anterior, Central and Posterior widths were 28.5, 26.4 and 21.3mm on right side and 26.1, 24.4 and $22.7 \mathrm{~mm}$ on left side.Medial Articular Surface: Mean central height on the medial articular surface was $12.4 \mathrm{~mm}$ on the right side and $10.2 \mathrm{~mm}$ on the left side, Mean central width on the medial articular surface was $24.0 \mathrm{~mm}$ on the right side and 18.2mm on the left side. Lateral Articular Surface:Mean central height on the lateral articular surface was $22.14 \mathrm{~mm}$ on the right side and $26.0 \mathrm{~mm}$ on the left side. Mean central width on the lateral articular surface was $20.8 \mathrm{~mm}$ on the right side and $16.3 \mathrm{~mm}$ on the left side.

Conclusion:The trochlear articular surface is wider in front, measurements of opposite talus bone can be used as a control during talus bone replacement surgery, it may help surgeons to plan pre-operatively to design accurate talus bone prosthesis and talus implants.
\end{abstract}

Keywords: Articular facets, Talus, Trochlear surface, Comma shapedfacet, Triangular facet.

\section{Introduction}

Talus receives the whole weight of the Body and transmits it to the tarsal bones. Talus forms the connecting link between the bones of the foot and the leg. The superior surface and adjacent medial and lateral surfaces of the Body of Talus are received by the Tibio-fibular mortice and form the ankle joint [1]. The talar trochlear surfaces is convex parasagittally and gently concave transeversely, being wider in front. The talar articular surface for medial malleolus is fairly flat, coma shaped and deeper anteriorly. The larger lateral talar articular surface is triangular and vertically concave [2]. A clear understanding of these articular surfaces has applications in designing of ankle braces to ankle implants and in total ankle replacements. Till today, studies have been done on talar morphological features like length, breadth, height, volume, Angles of declination and inclination, Anatomical variations of trochlear surface etc. $[3,4,5]$. That is the reason we have taken this topic.

\section{Material and methods:}

The study was conducted on dry Human Tali. The Human Tali were obtained from the bone collection of the Department of Anatomy of Osmania and Kakathiya Medical College in Telangana Region. 42 Dry Human Tali (20 Right and 22 Left) undamaged Human Tali were selected for the study. These Human Tali were of undetermined gender and age separated into right side and left side Tali. Each right and left Human Tali were assigned a serial number. Anatomical measurements were taken on human Tali using a vern iercaliper.

1. On the Trochlear surface: Medial length, Central length, Lateral length, anterior width, Central width, Posterior width (Fig1)

2. On the lateral triangular articular facet: Central height, Central width (Fig 2).

3. On the coma shaped medial articular facet: Central height, Central width (Fig 3).

The Data was tabulated and Analysed. Range and Mean values of each measurement were calculated. Compare the difference between Right and Left sides of measurements. 


\section{Results}

Superior Articular Surface:On the superior Articular surface, the mean values of Medial, Central and Lateral length were 28.4,29.4 and $28.4 \mathrm{~mm}$ on Right side and 31.0, 28.0 and $30.0 \mathrm{~mm}$ on Left side. Mean Anterior, Central and Posterior widths were 28.5, 26.4 and $21.3 \mathrm{~mm}$ on right side and 26.1, 24.4 and $22.7 \mathrm{~mm}$ on left side.

Medial Articular Surface: Mean central height on the medial articular surface was $12.4 \mathrm{~mm}$ on the right side and $10.2 \mathrm{~mm}$ on the left side, Mean central width on the medial articular surface was $24.0 \mathrm{~mm}$ on the right side and $18.2 \mathrm{~mm}$ on the left side.

Lateral Articular Surface: Mean central height on the lateral articular surface was $22.14 \mathrm{~mm}$ on the right side and $26.0 \mathrm{~mm}$ on the left side. Mean central width on the lateral articular surface was $20.8 \mathrm{~mm}$ on the right side and $16.3 \mathrm{~mm}$ on the left side.

\section{Discussion}

This measurements shows that trochlear articular surface is wider in front. The comparision of the measurements taken on the superior articular surface of the body of Talus between right and left tali were almost similar with little significant difference. Mean values of Medial, central and lateral lengths were higher in the study done by Dr. ShishirKumar(6) when compare to present study. Gautham K[7] found in his study the mean maximum transeverse width on the body of Talus was $37.94 \mathrm{~mm}$ on the right side and $36.80 \mathrm{~mm}$ on the left side which was higher compared to present study. Mean Trochlear length was $30.62 \mathrm{~mm}$ on right side and $30.44 \mathrm{~mm}$ on the left side. Ilhan Otag[8] found in his study that the mean values of talar width, Trochlear length and Trochlear breadth were 40.79, 33.45 and $31.69 \mathrm{~mm}$ on right side and 43.39, 34.12 and $31.72 \mathrm{~mm}$ on the left side respectively which were higher compared to present study.

\section{Conclusion}

The trochlear articular surface is wider infront, there is no significant difference between right and left sides of measurements. The difference in the mean values compared to other studies may be due to inherent population variations which may be because of genetic and environmental factors like climate, nutrition etc. As there is no significant difference between right and left sides of measurements, measurements of opposite talus bone can be used as a control during talus bone replacement surgery, it may help surgeons to plan pre-operatively the complex talar fracture surgeries, to design accurate talus bone prosthesis and talus implants[9].

\section{References}

[1]. Datta AK. Essentials of Human Anatomy, Part 3, 3rd Edition, Current Books Internationals. 2004; 151-52.

[2]. Gray's Anatomy. The Anatomical Basis of clinical Practice. 40th Edition, Elsevier Churchil Livingstone. $2008 ; 4279$.

[3]. Javia MD, Patel MM, Kubavat DM, Dixit Daksha, Singel TC. Morphometry of the Talus on the Basis of Sexual Dimorphism. Indian Journal of Research. June 2013, 3(5): 208-12.

[4]. Motagi MV, Kottapurath SR, Dharwadkar Kavitarati. Morphometric analyses of human dry tali of South Indian origin. International Journal of Medical Science and Public Health 2015;4(2): 237-40.

[5]. Khadija I, Sundus A, Shirza N. Anatomical Variations of Trochlear surface of Talus. JUMDC 2012; 3(1): 38-41.

[6]. Shishirkumar, Dr. Nambiar S, Dr. Arunachalam Kumar, Dr. Patil GV. Morphometric Analysis of Superior Articulating surface of Talus International Journal of science and research, 2014; 3(6): 2387-91.

[7]. Gautham K, Clarista MQ, Sheela N, Vidyashambhava P. Morphometric Analysis of The Human Tali. CIBTech Journal of Surgery, 2013; 2(2): 64-68.

[8]. Otag I, Cimen M. Morphometric Measures of Talus Bone in Skeleton Remains Belonging to Anatolian Geography. Indian Journal of Applied Research. 2003, 3(8), 530-31.

[9]. K. Islam, A. Dobbe, A. Komeili, K. Duke, M. El-Rich, S. Dhillon, S. Adeeb, N. M. Jomha. Symmetry analysis of talus bone. A Geometric morphometric approach. Bone Joint Res. May 2014; 3(5): 139-45.

Table1: Range and Mean of measurements of the articular facet on Superior articular surface of body of Talus, comparison between right and left sides.

\begin{tabular}{|l|l|l|l|l|}
\hline \multicolumn{5}{|c|}{ Trochlear surface of Talus } \\
\hline Parameter & $\begin{array}{l}\text { Right side } \\
\text { (range } \\
\text { parameter) }\end{array}$ & $\begin{array}{l}\text { Right side } \\
\text { (mean value) }\end{array}$ & $\begin{array}{l}\text { left side } \\
\text { (range of } \\
\text { parameter) }\end{array}$ & $\begin{array}{l}\text { Left } \\
\text { (mean value) }\end{array}$ \\
\hline Medial Length & $20-40 \mathrm{~mm}$ & 28.4 & $20-40 \mathrm{~mm}$ & 31.0 \\
\hline Central Length & $21-35 \mathrm{~mm}$ & 29.4 & $20-40 \mathrm{~mm}$ & 28.0 \\
\hline Lateral Length & $20-40 \mathrm{~mm}$ & 28.4 & $22-45 \mathrm{~mm}$ & 30.0 \\
\hline Anterior Width & $22-35 \mathrm{~mm}$ & 28.5 & $20-30 \mathrm{~mm}$ & 26.1 \\
\hline Central Width & $20-30 \mathrm{~mm}$ & 26.4 & $20-30 \mathrm{~mm}$ & 24.4 \\
\hline
\end{tabular}




\begin{tabular}{|l|l|l|l|l|}
\hline $\begin{array}{l}\text { Posterior } \\
\text { Width }\end{array}$ & $16-30 \mathrm{~mm}$ & 21.3 & $15-25 \mathrm{~mm}$ & 22.7 \\
\hline
\end{tabular}

Table2: Range and Mean of measurements of the articular facet on Lateral surfaces of body of Talus, comparison between right and left sides.

\begin{tabular}{|l|l|l|l|l|}
\hline \multicolumn{5}{|c|}{ Lateral triangular Articular Facet } \\
\hline parametrer & $\begin{array}{l}\text { Right side (range } \\
\text { of parameter) }\end{array}$ & $\begin{array}{l}\text { Right side } \\
\text { (mean value) }\end{array}$ & $\begin{array}{l}\text { Left side } \\
\text { (range of } \\
\text { parameter) }\end{array}$ & $\begin{array}{l}\text { Left side } \\
\text { (mean value) }\end{array}$ \\
\hline $\begin{array}{l}\text { Central } \\
\text { Height }\end{array}$ & $20-35 \mathrm{~mm}$ & 26.0 & $18-30 \mathrm{~mm}$ & 22.7 \\
\hline $\begin{array}{l}\text { Central } \\
\text { Width }\end{array}$ & $15-25 \mathrm{~mm}$ & 20.8 & $14-25 \mathrm{~mm}$ & 16.3 \\
\hline
\end{tabular}

Table3: Range and Mean of measurements of the articular facet on Medial surface of body of Talus, comparison between right and left sides.

\begin{tabular}{|l|l|l|l|l|}
\hline \multicolumn{7}{|c|}{ Coma shaped medial Articular Facet } \\
\hline parameter & $\begin{array}{l}\text { Right side } \\
\text { (range of } \\
\text { parameter) }\end{array}$ & $\begin{array}{l}\text { Right side } \\
\text { (mean } \\
\text { value) }\end{array}$ & $\begin{array}{l}\text { Left side } \\
\text { (range of } \\
\text { parameter) }\end{array}$ & $\begin{array}{l}\text { Left side } \\
\text { (mean value) }\end{array}$ \\
\hline $\begin{array}{l}\text { Central } \\
\text { Height }\end{array}$ & $10-28 \mathrm{~mm}$ & 12.4 & $08-15 \mathrm{~mm}$ & 10.2 \\
\hline Central Width & $15-30 \mathrm{~mm}$ & 24.0 & $10-25 \mathrm{~mm}$ & 18.2 \\
\hline
\end{tabular}

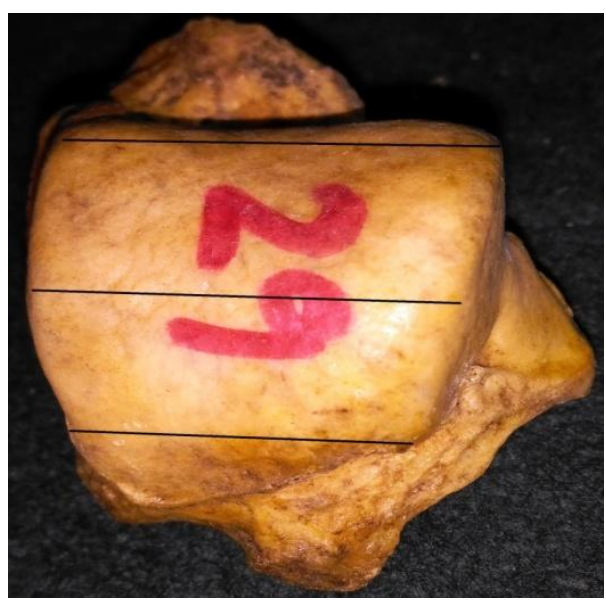

(a)

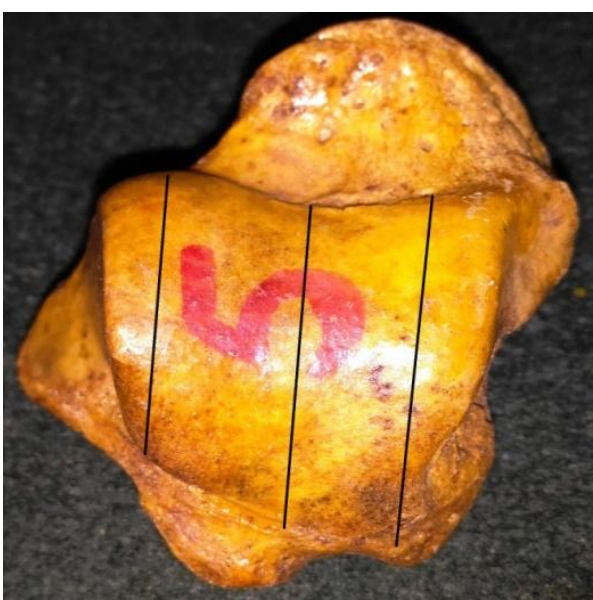

(b)

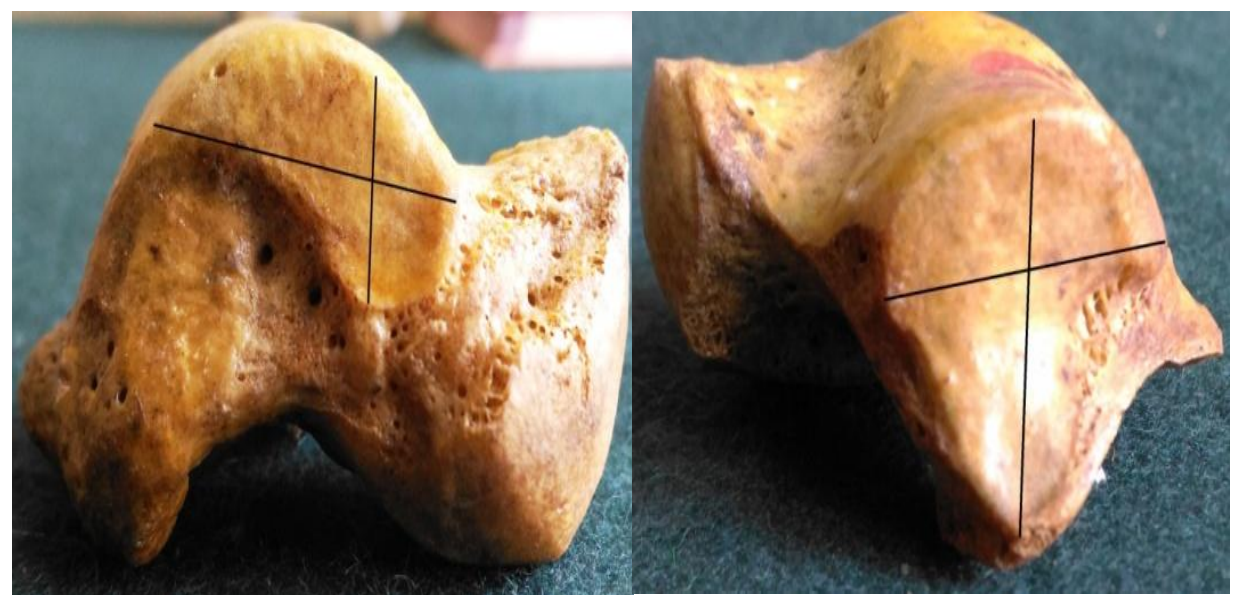

(c)

(d)

Fig: 1 Showing measurements of Articular facets of talus (a) \& (b) Superior articular surface,(c)Coma shaped facet on medial surface, (d)Triangular facet on lateral surface. 